\title{
Intraocular Hemorrhage After Transoral Endoscopic Thyroidectomy Vestibular Approach
}

\author{
Joon Hyung Kim', Gwi Eun Yeo ${ }^{2}$, Taehoon Kim², and Yong Tae Hong ${ }^{3}$ (D) \\ ${ }^{1}$ Department of Ophthalmology, Jeonbuk National University Medical School, Jeonju; and \\ ${ }^{2}$ Department of Anesthesiology and Pain Medicine, Jeonbuk National University Medical School, Jeonju; and \\ ${ }^{3}$ Department of Otolaryngology-HNS, Research Institute for Clinical Medicine of Jeonbuk National University-Biomedical Research \\ Institute of Jeonbuk National University Hospital, Jeonju, Korea
}

\author{
구강 내시경 갑상선 절제술 후 발생한 안구 내 출혈 \\ 김준형 ${ }^{1} \cdot$ 여귀은 $^{2} \cdot$ 김태훈 $^{2} \cdot$ 홍용태 $^{3}$ \\ 전북대학교 ${ }^{1}$ 안과학교실, ${ }^{2}$ 마취통증의학교실, ${ }^{3}$ 이비인후과학교실
}

\author{
Received April 12, 2021 \\ Revised August 4, 2021 \\ Accepted August 16, 2021 \\ Address for correspondence \\ Yong Tae Hong, MD, PhD \\ Department of Otolaryngology-HNS, \\ Research Institute for Clinical \\ Medicine of Jeonbuk National \\ University-Biomedical Research \\ Institute of Jeonbuk National \\ University Hospital, \\ 20 Geonji-ro, Deokjin-gu, \\ Jeonju 54907, Korea \\ Tel $+82-63-250-1990$ \\ Fax $+82-63-250-1986$ \\ E-mail centennialman \\ @)hanmail.net
}

\begin{abstract}
Transoral endoscopic thyroid surgery vestibular approach (TOETVA) is now widely performed globally with good cosmetic outcomes. However, there are complications related to this approach which surgeons should be aware of. We report here a 41-year-old female patient who had an unusual ocular complication after total thyroidectomy via TOETVA. She was diagnosed with papillary thyroid carcinoma and received total thyroidectomy via TOETVA. She complained of floating particles in her right eye immediately after the operation. Fundus examination revealed intraocular hemorrhage in her right eye. At one-month follow-up, all of the intraocular hemorrhage was improved by fundus examination, resolving her chief complaint. Surgeons and anesthesiologists should be aware of increased intracranial pressure during the TOETVA and possible ocular complications after the surgery, although they are rare.
\end{abstract}

Korean J Otorhinolaryngol-Head Neck Surg 2022;65(6):343-6

Keywords Eye hemorrhage; Thyroid cancer; Thyroidectomy.

\section{Introduction}

Transoral endoscopic thyroid surgery vestibular approach (TOETVA) is gaining popularity globally as it leads to excellent cosmetic outcomes. Also, this approach is a minimally invasive approach as it requires less flap elevation compared to other remote access thyroidectomy approaches. ${ }^{1)}$ Recent studies have also demonstrated that this approach can be safely adopted for thyroid cancer patients. ${ }^{2)}$ However, there are complications related to this approach which the surgeons should

This is an Open Access article distributed under the terms of the Creative Commons Attribution Non-Commercial License (https://creativecommons.org/licenses/by-nc/4.0) which permits unrestricted non-commercial use, distribution, and reproduction in any medium, provided the original work is properly cited. be aware of such as mental nerve injury, oral commissure tearing, chin flap perforation, $\mathrm{CO} 2$ embolism, and subcutaneous emphysema. ${ }^{3,4)}$ To date, we have experienced more than 70 cases of TOETVA in a tertiary hospital in South Korea. Recently, we encountered a intraocular hemorrhage after total thyroidectomy via TOETVA, in a female patient with thyroid cancer. To our knowledge, in reviewing of English literature, this is a first report regarding intraocular hemorrhage after TOETVA.

\section{Case}

An age 41 female patient which diagnosed with papillary 
thyroid carcinoma by fine needle aspiration cytology in her both thyroid lobes was scheduled for total thyroidectomy. Although she needed total thyroidectomy to eradicate her malignant tumors, she strongly wanted a scar-less approach and decided to receive TOETVA. She had no history of underlying chronic disease. Also, preoperative laboratory tests, electrocardiography, and chest X-ray were in the normal range. When she arrived at the operation room, she was monitored for pulse oximetry, electrocardiogram, blood pressure, and bispectral index (BIS) monitor (BIS Vista ${ }^{\mathrm{TM}}$, Aspect Medical Systems InC., Newton, MA, USA). Her pre induction blood pressure was $127 / 73 \mathrm{~mm} \mathrm{Hg}$, heart rate was 86 beats/minute, and peripheral arterial oxygen saturation level was $99 \%$. For induction and maintenance of anesthesia, propofol and remifentanil were administered with a target-controlled infusion device (Orchestra ${ }^{\circledR}$ Base Primea, Fresenius Kabi, Brezins, France). Infusion was started with the target effect-site concentration (CeT) of propofol $5 \mu \mathrm{g} / \mathrm{mL}$ and remifentanil $3 \mathrm{ng} / \mathrm{mL}$, and after loss of consciousness, rocuronium $40 \mathrm{mg}$ was administered and then tracheal intubation was performed. Recurrent laryngeal nerve monitoring was applied throughout the operation. No additional muscle relaxant was administered after anesthesia induction. The patient was placed supine with neck hyperextension by inserting a soft pillow under the shoulder and in a $15^{\circ}$ Trendelenburg bed position (Fig. 1). Our detailed surgical technique was based on the Anuwong, et al. ${ }^{5)}$ report. Briefly, after three incisions were performed in the oral vestibule, tree trocars were inserted. The pressure of inflating $\mathrm{CO} 2$ was set at $6 \mathrm{~mm} \mathrm{Hg}$ with high flow and the anesthesiologist monitored the end-tidal CO2 level during the operation. After the subcutaneous flap was raised, total thyroidectomy with central neck dissection was performed in the usual manner (Fig. 1B).
We placed a surgical drainage tube through the small puncture on the axillary area. During the whole operation, blood pressure and other vital signs were stable and end tidal carbon dioxide concentration, and body temperature were $33-$ $38 \mathrm{~mm} \mathrm{Hg}$ and $36.6^{\circ} \mathrm{C}-36.9^{\circ} \mathrm{C}$, respectively. Total anesthetic duration was 258 minutes and total operation time was 203 minutes. After confirming consciousness and the reversal of the muscle blockade, extubation was performed and the patient was transferred to the post anesthesia care unit. Her postoperative outcome was uneventful except that she complained of floating particles in her right eye at operative day. She was referred to the ophthalmologic department for further evaluation. Her visual acuity was 20/20 and intraocular pressure was $13 \mathrm{~mm} \mathrm{Hg}$ in both eyes which were in normal range. There were no specific findings in the anterior segment of the eye, but there were optic disc hemorrhage, small amount of retinal hemorrhage, and vitreous hemorrhage by fundus examination in her right eye (Fig. 2). We realized that the patient's symptom began immediately after recovery of her consciousness in the post anesthesia care unit by detailed medical interview. The patient was discharged on postoperative day four with discomfort in her right eye. At one-month follow-up, all of the intraocular hemorrhage was improved by fundus examination and her chief complaint was resolved.

\section{Discussion}

Although, TOETVA is now spreading rapidly globally and accepted as a safe approach, it has specific complications such as mental nerve injury, oral commissure tearing, chin flap perforation, CO2 embolism, and subcutaneous emphysema.,4) Corneal abrasion has been reported as the most common oc-
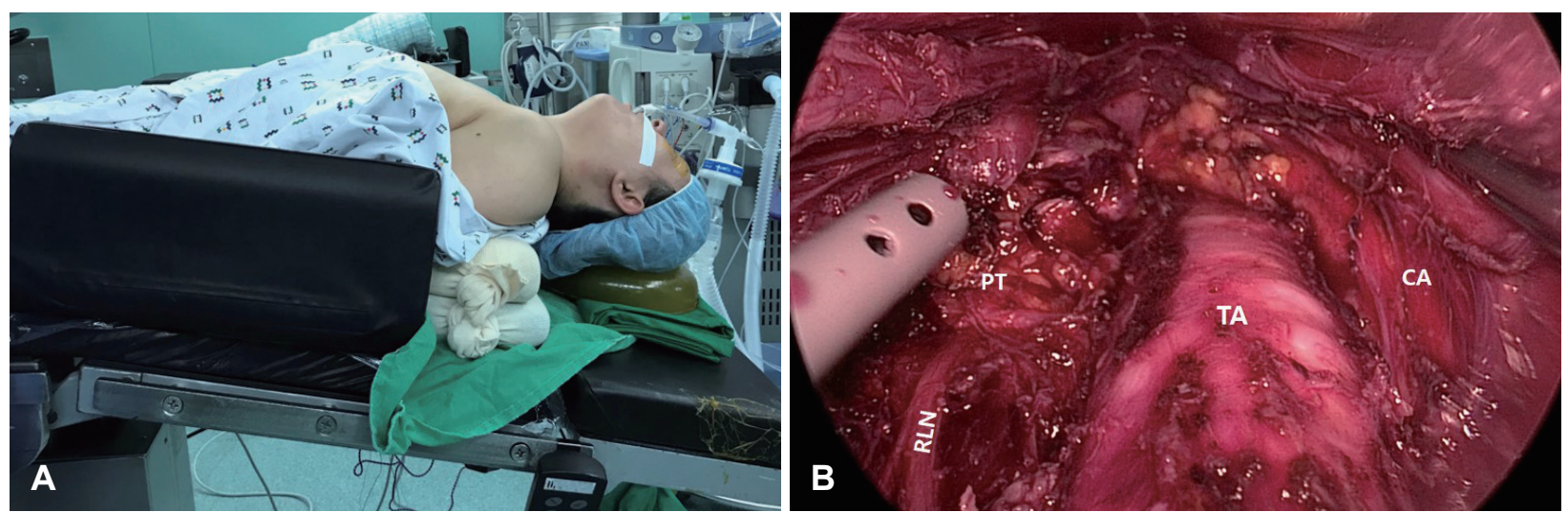

Fig. 1. The patient's position and intraoperative view. A: The patient's position during the operation. The patient was placed supine with neck hyperextension by inserting a soft pillow under the shoulder and in a $15^{\circ}$ Trendelenburg bed position. B: Endoscopic view after completion of total thyroidectomy with central neck dissection via trans-oral approach. TA, trachea; RLN, recurrent laryngeal nerve; PT, parathyroid gland; CA, carotid artery. 

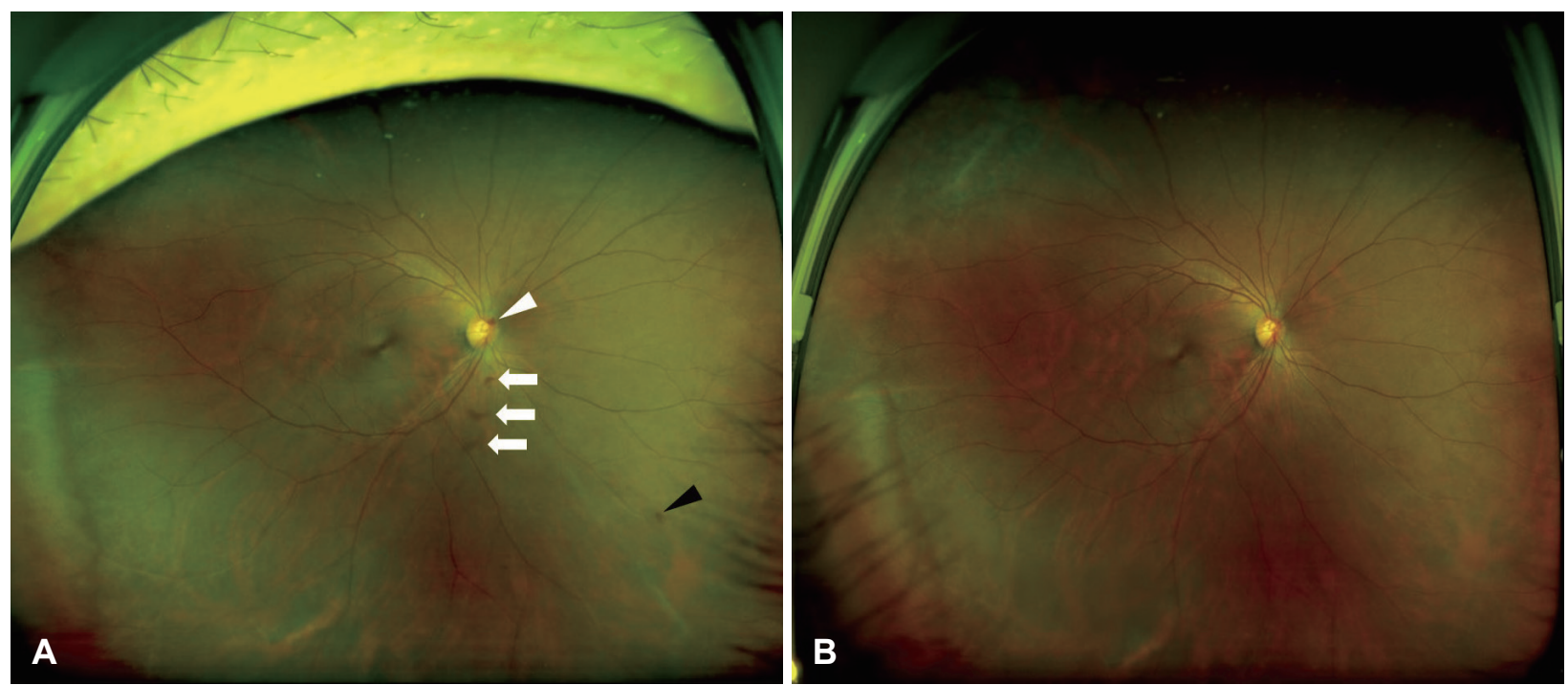

Fig. 2. Wide fundus photographies of the patient. A: Wide fundus photography of the patient at first visit. There were optic disc hemorrhage, small amount of retinal hemorrhage, and vitreous hemorrhage. B: Wide fundus photography of the patient at follow-up a month later. All kinds of intraocular hemorrhages were improved. Optic disc hemorrhage: white arrow head, vitreous hemorrhages: white arrows, retinal hemorrhage: black arrow head.

ular complication after non-ocular surgery under general anesthesia. ${ }^{6}$ However, intraocular hemorrhage after TOETVA has not been reported.

There are many causes of intraocular hemorrhage such as trauma, retinal detachment, chorioretinitis, coagulation factor disorders, diabetic retinopathy, retinal vein occlusion, Terson syndrome, and hypertensive retinopathy. In this case, the patient had no systemic disease or other specific ophthalmologic findings except that during the operation intracranial pressure (ICP) may have increased because of the patient's position and $\mathrm{CO} 2$ insufflation.

Terson syndrome is one of the diseases characterized by vitreous hemorrhage and retinal hemorrhage caused by subarachnoid hemorrhage or elevated ICP. ${ }^{7)}$ Optic disc hemorrhage also occurs with increased ICP. ${ }^{8)}$ The mechanism of intraocular hemorrhage from increased ICP is unclear, but it is known that increased ICP is transmitted through the intervaginal space of optic nerve sheath, causing damage to peripapillary tissues. ${ }^{9)}$

There have been few reports of intraocular hemorrhage after the non-ocular surgery in reviewing the English literatures. Intraocular hemorrhage were occurred after endoscopic spinal surgery, in which it was assumed that ICP might spikes if the dura is inadvertently punctured during the operation and fluid is infused into the subarachnoid space. ${ }^{10)}$ And, there was a report of intraocular hemorrhage after local anesthetic dental implant surgery, in which Valsalva maneuver during the procedure might increase ICP and led to intraocular hemorrhage. ${ }^{11)}$
There are many intraoperative factors which influence ICP. Physiologic and anesthetic factors other than surgical factors are main contributors. The neck extension and $15^{\circ}$ Trendelenburg bed position could affect the ICP in TOETVA. Neck extension can elevate ICP because the internal jugular vein, the main pathway for cranial blood, may functionally deteriorate and cerebral venous return may be relatively compromised. ${ }^{12)}$

Additionally, the operative cavity is maintained mainly by CO2 insufflation during the TOETVA. It can cause further complications such as subcutaneous emphysema of the neck and hypercarbia. ${ }^{13)}$ The end tidal carbon dioxide concentration is another factor that could affect the ICP as hypoventilation induced by increasing carbon dioxide levels results in the vasodilation of blood vessels and elevates the ICP. ${ }^{14)}$ A Hvidber, et al. ${ }^{15)}$ reported elevated carbon dioxide level and change in body position during the general anesthisa directly affects the intraocular pressure.

Generally, TOETVA proceeds over one hour. Also, this patient's procedure consumed more than three hours for TOETVA, as we performed total thyroidectomy and central neck dissection to eradicate her malignant thyroid tumor.

The patient in this case had no special history that caused intraocular hemorrhage and no evidence of idiopathic intracranial hypertension in preoperative examination. Thus, we deduced the cause of intraocular hemorrhage from increased ICP can be attributable to the extension of the neck in the $15^{\circ}$ Trendelenburg bed position, carbon dioxide insufflation, and prolonged operation duration. 
In conclusion, surgeons and anesthesiologists should be aware of acute increased ICP during the TOETVA, although rare.

\section{Acknowledgments}

This paper was supported by Fund of Biomedical Research Institute of Jeonbuk National University Hospital.

\section{Author Contribution}

Conceptualization: Gwi Eun Yeo, Taehoon Kim, Yong Tae Hong. Data curation: Gwi Eun Yeo, Taehoon Kim. Formal analysis: Taehoon Kim, Yong Tae Hong. Funding acquisition: Yong Tae Hong. Investigation: Taehoon Kim. Methodology: Joon Hyung Kim. Project administration: Joon Hyung Kim. Resources: Gwi Eun Yeo, Taehoon Kim. Software: Gwi Eun Yeo, Taehoon Kim. Supervision: Yong Tae Hong. Validation: Yong Tae Hong. Visualization: Joon Hyung Kim. Writing — original draft: Joon Hyung Kim, Gwi Eun Yeo, Yong Tae Hong. Writing — review \& editing: Joon Hyung Kim, Yong Tae Hong.

\section{ORCID}

Yong Tae Hong https://orcid.org/0000-0001-7584-5823

\section{REFERENCES}

1) Inabnet WB 3rd, Fernandez-Ranvier G, Suh H. Transoral endoscopic thyroidectomy - An emerging remote access technique for thyroid excision. JAMA Surg 2018;153(4):376-7.

2) Ahn JH, Yi JW. Transoral endoscopic thyroidectomy for thyroid carcinoma: Outcomes and surgical completeness in 150 singlesurgeon cases. Surg Endosc 2020;34(2):861-7.

3) Zhang $D$, Wu CW, Inversini D, Kim HY, Anuwong A, Bacuzzi A, et al. Lessons learned from a faulty transoral endoscopic thyroidectomy vestibular approach. Surg Laparosc Endosc Percutan Tech 2018; 28(5):e94-9.

4) Kim KN, Lee DW, Kim JY, Han KH, Tae K. Carbon dioxide embolism during transoral robotic thyroidectomy: A case report. Head Neck 2018;40(3):E25-8.

5) Anuwong A, Ketwong K, Jitpratoom P, Sasanakietkul T, Duh QY. Safety and outcomes of the transoral endoscopic thyroidectomy vestibular approach. JAMA Surg 2018;153(1):21-7.

6) Malafa MM, Coleman JE, Bowman RW, Rohrich RJ. Perioperative corneal abrasion: Updated guidelines for prevention and management. Plast Reconstr Surg 2016;137(5):790e-8e.

7) Medele RJ, Stummer W, Mueller AJ, Steiger HJ, Reulen HJ. Terson's syndrome in subarachnoid hemorrhage and severe brain injury accompanied by acutely raised intracranial pressure. J Neurosurg 1998;88(5):851-4.

8) Wall M, Thurtell MJ; NORDIC Idiopathic Intracranial Hypertension Study Group. Optic disc haemorrhages at baseline as a risk factor for poor outcome in the Idiopathic Intracranial Hypertension Treatment Trial. Br J Ophthalmol 2017;101(9):1256-60.

9) Ogawa T, Kitaoka T, Dake Y, Amemiya T. Terson syndrome: A case report suggesting the mechanism of vitreous hemorrhage. Ophthalmology 2001;108(9):1654-6.

10) Moschos MM, Rouvas A, Papaspirou A, Apostolopoulos M. Acute visual loss and intraocular hemorrhages associated with endoscopic spinal surgery. Clin Ophthalmol 2008;2(4):937-9.

11) Krepier K, Wedrich A, Schranz R. Intraocular hemorrhage associated with dental implant surgery. Am J Ophthalmol 1996;122(5):745-6.

12) Gooding CA, Stimac GK. Jugular vein obstruction caused by turning of the head. AJR Am J Roentgenol 1984;142(2):403-6.

13) Yu W, Li F, Wang Z, Qi X, Li B, Zhang G, et al. Effects of CO2 insufflation on cere-brum during endoscopic thyroidectomy in a porcine model. Surg Endosc 2011;25(5):1495-504.

14) Yu J, Park JY, Kim DH, Koh GH, Kim S, Hwang JH, et al. Effect of neck extension on ultrasonographic optic nerve sheath diameter as a surrogate for intracranial pressure in patients under going palatoplasty: A prospective observational study. J Plast Reconstr Aesthet Surg 2020;73(2):369-75.

15) Hvidberg A, Kessing SV, Fernandes A. Effect of changes in $\mathrm{PCO} 2$ and body positions on intraocular pressure during general anaesthesia. Acta Ophthalmol (Copenh) 1981;59(4):465-75. 